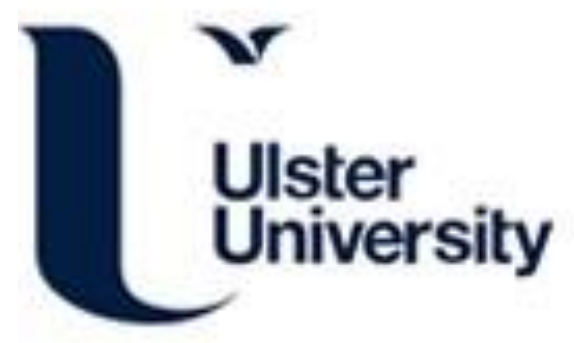

\title{
Development of Ganoderma lucidum spore powder based proteoglycan and its application in hyperglycemic, antitumor and antioxidant function
}

Zhu, L. F., Yao, Y., Ahmad, Z., \& Chang, M. W. (2019). Development of Ganoderma lucidum spore powder based proteoglycan and its application in hyperglycemic, antitumor and antioxidant function. Process Biochemistry, 84, 103-111. https://doi.org/10.1016/j.procbio.2019.05.025

Link to publication record in Ulster University Research Portal

\author{
Published in: \\ Process Biochemistry
}

Publication Status:

Published (in print/issue): 01/09/2019

DOI:

10.1016/j.procbio.2019.05.025

\section{Document Version}

Author Accepted version

\section{General rights}

Copyright for the publications made accessible via Ulster University's Research Portal is retained by the author(s) and / or other copyright owners and it is a condition of accessing these publications that users recognise and abide by the legal requirements associated with these rights.

\section{Take down policy}

The Research Portal is Ulster University's institutional repository that provides access to Ulster's research outputs. Every effort has been made to ensure that content in the Research Portal does not infringe any person's rights, or applicable UK laws. If you discover content in the Research Portal that you believe breaches copyright or violates any law, please contact pure-support@ulster.ac.uk. 
Li-Fang Zhu, ${ }^{1,2}$ Yuanfa Yao, ${ }^{1,2}$ Zeeshan Ahmad, ${ }^{3}$ Ming-Wei Chang ${ }^{1,2,4 *}$

${ }^{1}$ Key Laboratory for Biomedical Engineering of Education Ministry of China, Zhejiang University,

$7 \quad$ Hangzhou, 310027, PR China.

$82^{2}$ Zhejiang Provincial Key Laboratory of Cardio-Cerebral Vascular Detection Technology and

9 Medicinal Effectiveness Appraisal, Zhejiang University, Hangzhou, 310027, PR China.

$10{ }^{3}$ Leicester School of Pharmacy, De Montfort University, The Gateway, Leicester, LE1 9BH, UK.

$11{ }^{4}$ Nanotechnology and Integrated Bioengineering Centre, University of Ulster, Jordanstown

12 Campus, Newtownabbey, BT37 0QB, Northern Ireland, UK. 
obtained via solvent extraction and optimized using response surface methodology

21 (RSM). The differences among the characteristics of the new proteoglycan from

22 cracked (proteoglycan-C) and uncracked GLSP (proteoglycan-UC) were explored. The

23 SDS-PAGE results showed the molecular weight of protein contained in proteoglycan-

$24 \mathrm{UC}(55,72,95 \mathrm{kDa})$ was different to that proteoglycan-C $(43,95 \mathrm{kDa})$. The differences

25 of these amino acids (Glu, Arg, Leu and Lys) content and monosaccharides (Fuc, Gal,

26 Glc, Man and Gal-AC) content between proteoglycan-C and proteoglycan-UC were

27 determined by HPLC/ ion chromatography. The 2,2'-azino-bis (3-ethylbenzthiazoline-

28 6-sulphonic acid) (ABTS) and 1,1-Diphenyl-2-picrylhydrazyl (DPPH) radical

29 scavenging activities of proteoglycan-C were higher than that proteoglycan-UC. The

30 proteoglycan-UC exhibited stronger hypoglycemic and antibacterial effects against $E$.

31 coli and S. aureus, and the proteoglycan-C and proteoglycan-UC showed antitumor

32 effects with potential for therapeutic applications.

33

34 Keywords: proteoglycan; Ganoderma lucidum spore powder; hypoglycemic;

35 antibacterial; antitumor.

36 
effects and minor side effects of the products in prevention and alleviation of cancer,

40 hypertension and diabetes [1]. For example, Lentinan, a polysaccharide obtained from

41 the stipe portion of Lentinus edodes mushroom, revealed anticancer activities against

42 human colon cancer [2]. In addition, the proteoglycan obtained from Ganoderma

43 lucidum (G. lucidum) fruiting bodies has demonstrated protective effects on the kidneys

44 and amelioration of diabetic nephropathy [3].

G. lucidum is a well-known traditional Chinese medicine herb that has been used to

46 promote health and longevity for several thousands of years [4]. During the past few

47 decades, applications of G. lucidum have been explored and include alleviating

48 symptoms of asthma [5], promoting wound healing [6], as antitumor agents [7] and also

49 as an oral multidrug $[8,9]$. Among the bioactive ingredients, the proteoglycans and

50 polysaccharides have shown important roles in medicinal potencies [10]. The

51 proteoglycan is a kind of glycoprotein consisting of a core protein linked to one or more

52 glycosaminoglycan chains via covalent bonding [11], and shows efficient

53 hypoglycemic activity in vitro [12] as well as excellent anti-herpetic activities against

54 type 1 and type 2 herpes simplex virus has been revealed [13]. This suggests the

55 polysaccharides presence during the extraction of protein is advantageous with regards

56 to the bioactive effects of the proteoglycan. 

monosaccharide in cracked GLSP and uncracked GLSP were then explored through Fourier transform infrared spectroscopy (FTIR), High Performance Liquid

64 Chromatography (HPLC) and ion chromatography. Subsequently, the antioxidant,

65 antitumor and antibacterial effects of proteoglycan from cracked and uncracked GLSP were compared. In consideration of the widespread applications of proteoglycans and

67 G. lucidum, the results in this study may broaden the source of proteoglycans and

68 application of GLSP.

\section{2. Materials and methods}

\section{$71 \quad 2.1$ Materials}

GLSP (cracked and uncracked wall) was offered by TianHe Agricultural Group

73 (ZheJiang LongQuan, China). Sodium hydroxide (troche), ammonium sulfate (powder), methanol, absolute ethanol and hydrochloric acid were purchased from Sinopharm

75 Chemical Reagent Co., Ltd (Shanghai, China). Fetal bovine serum (FBS) was

76 purchased from Sijiqin (Sijiqin, Hangzhou, zhejiang, China), Dulbecco's modified

77 eagle's medium (DMEM) was purchased from Gibico (Gibco, USA) and deionized

78 water (DI) were offered by the Millipore Milli-Q Reference ultrapure water purifier 
electrophoresis (SDS-PAGE) Gel Quick Preparation Kit were offered by Shanghai Beyotime biotechnology Co., Ltd (Shanghai, China). Violet red bile agar, baird-parker agar base, adding egg-yolk tellurite emulsion, nutrient broth, $7.5 \%$ sodium chloride

86 broth were from Qingdao Hope Bio-Technology Co., Ltd (Shandong, China). Universal

87 indicator paper ( $\mathrm{pH}$ 1-14, Shanghai SSS reagent Co., Ltd). All chemicals were

88 analytical grade with no further purification before experimentation.

\subsection{Extraction of proteoglycan}

The proteoglycan was obtained using conventional water extraction via a water bath

92 (DZKW-D-4, Suzhou Jiangdong precise instrument Co., Ltd, Suzhou, China). Approximately $1 \mathrm{~g}$ of dried GLSP (uncracked) was dispersed with DI water according to a predetermined solid-to-liquid ratio, and then kept in the water bath at the predetermined temperature for predetermined time. The mixture was then centrifuged at $8000 \mathrm{rpm}$, at $4{ }^{\circ} \mathrm{C}$ for $30 \mathrm{~min}$ using Centrifuge $5810 \mathrm{R}$ (Eppendorf, Germany),

97 according the method in previous work [14]. The supernatant was collected and concentrated using Rotavapor (RE-52A, Shanghai, China) at $-0.09 \mathrm{MPa}$ and $55^{\circ} \mathrm{C}$ to one-tenth of the volume. Ammonium sulfate was introduced to the concentrated mixture until saturation. $\mathrm{NaOH}$ was introduced to achieve a neutral $\mathrm{pH}$ and left to stand 
protein assay reagent (Bio-Rad, USA). Since proteoglycan is similar to glycoprotein and there is no single standard for proteoglycan, BSA was used as a standard protein. Absorbance of BSA was examined at $595 \mathrm{~nm}$ using UV spectrophotometer (UV-2600, Shimadzu, Japan). The standard curve of concentration-absorbance was plotted (in Fig. S1), and fitting equation is shown in Eq. (1): where, $\mathrm{y}$ was the absorbance, $\mathrm{x}$ was the concentration $(\mathrm{mg} / \mathrm{mL})$. results from response surface methodology (RSM) (Design-Expert 8.0.6 Trial, StatEase, Inc. USA). Four three-level independent variables (Table S1) were selected based on the single factorial assays.

\subsection{Molecular weight determination of protein}

The protein molecular weight was determined using Sodium Dodecyl Sulfate Polyacrylamide Gel electrophoresis (SDS-PAGE) [16]. Each sample (20 $\mu \mathrm{L}, 10 \mathrm{mg} / \mathrm{mL})$ was determined in SDS-PAGE with a $6 \%$ resolving gel and a 5\% stacking gel (SDSPAGE Gel Quick Preparation Kit). The operation was performed at $100 \mathrm{~V}$ through stacking gel followed by $120 \mathrm{~V}$ to the end of resolving gel using Power Pac ${ }^{\mathrm{TM}}$ Basic 

spectroscopy (IR Affinity 1, Shimadzu, Japan). The samples were grounded with $\mathrm{KBr}$ powder and then pressed into pellet using powder compressing machine (FW-4A, Tianjin TUOPU instrument Co., Ltd, Tianjin, China) under the pressure $\sim 14 \mathrm{MPa}$ for 2 min, and getting the spectrum with 20 scans at a resolution of $4 \mathrm{~cm}^{-1}\left(4000-400 \mathrm{~cm}^{-1}\right)$.

\subsection{Amino acid and monosaccharide composition of proteoglycan}

The amino acid content of the protein was determined using a High Performance

Liquid Chromatography system (HPLC, UitMate 3000, Thermo-Fisher Scientific, USA), which was equipped with a DAD-3000 (RS) fluorescence detector. The analyte was separated using an analytical column ZORBAX Eclipse-AAA $(4.6 \mathrm{~mm} \times 150 \mathrm{~mm}$, Agilent ZORBAX Eclipse, Agilent Technology, USA). The mobile phase consisted of $\mathrm{Na}_{2} \mathrm{HPO}_{4}(\mathrm{pH} 7.8)$ with a concentration of $40 \mathrm{mM}$ and acetonitrile-methanol-DI (45: 45: $10, \mathrm{v} / \mathrm{v} / \mathrm{v})$.

The monosaccharide was detected using an ion chromatograph system (Dionex ICS5000, Thermo-Fisher Scientific Dionex, USA) combining a chromatographic guard column (3 mm $\times 50 \mathrm{~mm}$, Dionex Carbo PAC ${ }^{\mathrm{TM}}$ PA20) and anion exchange column (3 
The ABTS radical scavenging activity was determined using a total antioxidant capacity assay kit. In brief, the ABTS radical solution and trolox standard solution with various concentrations $(0.1,0.2,0.4,0.6,0.8,1.0 \mathrm{mM})$ were prepared according to manufacturer instructions. Peroxidase stock solution was added to a 96-well plate (20 $\mu \mathrm{L} /$ well). DI water was used as blank control, trolox standard solution was added for the positive control and sample solution was added for the sample group (10 $\mu \mathrm{L} /$ well). Following that, ABTS radical solution was added $(170 \mu \mathrm{L} /$ well) and the plate was cultured for 6 minutes at $25^{\circ} \mathrm{C}$. The absorbance was measured at $414 \mathrm{~nm}$ using Spectra Max 190 microplate reader (NanoDrop, USA). The antioxidant activity of sample was shown as Trolox equivalent antioxidant capacity (TEAC) and calculated as Eq. (2), according to previous works $[14,17]$ :

TEAC $(\mathrm{mM}$ Trolox $/ \mathrm{mg}$ protein of sample $)=\frac{A_{s}-A_{b}}{A_{b}} \times \frac{1}{m X}$

161 Where, the $A_{s}$ is the absorbance of sample; the $A_{b}$ is the absorbance of blank control; the $m$ is slope of a plot between antioxidant capacity and mM Trolox; the $X$ is $\mathrm{mg}$ protein of sample. Yang et al. [18]. Using DI water and ethanol to dissolve proteoglycan and DPPH, to the 

control, which the DPPH was replaced by ethanol in equal volume; the $A_{b}$ is the absorbance of blank, which the sample solution was replaced by DI water in equal volume.

\subsection{Hypoglycemic activity assay in vitro}

\subsubsection{Hypoglycemic effect on normal HepG2 cells}

HepG2 (human hepatocellular liver carcinoma) cells (ca. $1.4 \times 10^{5}$ cells $/ \mathrm{mL}$ ) were cultured in DMEM supplemented with 10\% FBS and 1\% penicillin-streptomycin in cell culture dishes (diameter, $\Phi=6 \mathrm{~cm})$ under standard conditions $\left(37{ }^{\circ} \mathrm{C}, 5 \% \mathrm{CO}_{2}\right)$ for 48

h. Then, pipetted cell suspensions into a 96-well plate $(100 \mu \mathrm{L} /$ well $)$ and incubated in serum-free DMEM at standard conditions for $12 \mathrm{~h}$. Following this, cells for blank control were incubated in serum-free DMEM, and cells for positive control were incubated in serum-free DMEM supplemented with metformin $\left(1 \times 10^{-3} \mathrm{~mol} / \mathrm{L}\right)$. The treatment groups were incubated in serum-free DMEM supplemented with various concentrations of proteoglycan $(0.1,1,10 \mathrm{mg} / \mathrm{mL})$. After being incubated $24 \mathrm{~h}$, measuring the glucose content of supernatant of media using Micro Blood Sugar 
HepG2 cells (ca. $1.4 \times 10^{5}$ cells $/ \mathrm{mL}$ ) were seeded into a 12 -well plate for $24 \mathrm{~h}$ in serum-

free DMEM. The cells were then treated with serum-free DMEM with insulin $\left(1 \times 10^{-}\right.$ ${ }^{7} \mathrm{~mol} / \mathrm{L}$ ) for $1 \mathrm{~h}$. Subsequently, the cells were incubated in serum-free DMEM with metformin $\left(1 \times 10^{-3} \mathrm{~mol} / \mathrm{L}\right)$ or various concentrations of proteoglycan $(1,5,10 \mathrm{mg} / \mathrm{mL})$ for $24 \mathrm{~h}$. Finally, the glucose content of supernatant of media was measured by using UV-Vis.

\subsection{Antitumor activities assay in vitro}

\subsubsection{Cell viability assay}

The antitumor effects of proteoglycan on tumor cell lines were determined using CCK-8 (cell counting Kit-8 reagent, Dojindo Laboratories, Kumamoto, Japan) assay [20]. In brief, HeLa cell suspension (ca. $1.4 \times 10^{5}$ cells $/ \mathrm{mL}$ ) was obtained after being cultured in DMEM supplemented with 10\% FBS and 1\% penicillin-streptomycin in cell culture dishes $(\Phi=6 \mathrm{~cm})$ under standard conditions for $48 \mathrm{~h} .100 \mu \mathrm{L}$ cell suspensions were pipetted into a 96-well plate and incubated at standard conditions for $24 \mathrm{~h}$. For treatment group, $100 \mu \mathrm{L}$ each well of proteoglycan solution was added after being disinfected using UV radiation for $4 \mathrm{~h}$; and $100 \mu \mathrm{L}$ medium was added to the control. 


\subsubsection{AO/EB staining}

HeLa cells were stained using AO/EB dye mixture. In brief, cell suspension $\left(1.4 \times 10^{5}\right.$ cells $/ \mathrm{mL}$ ) were seeded into a 6-well plate. After being incubated $24 \mathrm{~h}$ for adherence, the cells were treated with proteoglycan solution with various concentrations ( 1 or 5 $\mathrm{mg} / \mathrm{mL})$ for another 48 h. $20 \mu \mathrm{L}$ of AO/EB dye mixture $(100 \mu \mathrm{g} / \mathrm{mL}$ EB and $100 \mu \mathrm{g} / \mathrm{mL}$ AO into the 6-well plate and left to stand for $30 \mathrm{~min}$ at $37^{\circ} \mathrm{C}$. The plate was analyzed using fluorescence microscopy (Olympus, BX61W1-FV1000, Tokyo, Japan).

\subsection{Antibacterial activity assay}

The antibacterial effects of proteoglycan on E. coli (NW1014 (8099), Nanjing (CMCC(B)26003, Shanghai Luwei Microbial SCI. \& TECH. Co., Ltd, China) was studied using the method [22]. Pressing proteoglycan powder (ca. $100 \mathrm{mg}$ ) to a disk by the powder compressing machine. Coating $0.2 \mathrm{~mL}\left(1.2 \times 10^{6} \mathrm{CFU} / \mathrm{mL}\right)$ inoculums of $E$. coli and S. aureus on violet red bile agar and baird-parker agar base plates adding egg- 

added into $100 \mathrm{~mL}$ nutrient broth and $7.5 \%$ sodium chloride broth respectively, and then incubated in the biochemical incubator at $37^{\circ} \mathrm{C}$ for $24 \mathrm{~h}$. After that, using $25 \mu \mathrm{g} / \mathrm{mL}$ FDA and PI to stain the bacteria for $20 \mathrm{~min}$ at $25^{\circ} \mathrm{C}$ and was kept away from light. The fluorescence value was measured using a fluorescence microplate reader (FlexStation II, NanoDrop, USA), and the fluorescence value was calculated using previous method [22].

\subsection{Statistical analysis} deviation $(n=3)$. Statistical analysis was performed using SPSS software (SPSS Statistics v18, IBM, UK). The one-way analysis of variance (ANOVA) were revealed using RSM (Design- Expert 8.0.6 Trial, Stat-Ease, Inc., USA). All the statistical plots were plotted using Origin software (OriginLab, USA).

\section{Results and discussion}

\subsection{Optimization of the proteoglycan extraction}


effects on yields. The experimental data and results are shown in Table S2. Then, the regression equation was obtained according to the results of ANOVA:

$\mathrm{Y}=3.93+0.027 \times \mathrm{A}-0.044 \times \mathrm{B}+0.044 \times \mathrm{C}+0.12 \times \mathrm{D}-0.20 \times \mathrm{A} \times \mathrm{B}+0.099 \times \mathrm{A} \times \mathrm{C}+0.079 \times \mathrm{A} \times \mathrm{D}-$

where, $\mathrm{Y}$ is the proteoglycan yield (\%) in the resultant product probably; A, B, C and

D was the solid-liquid ratio, time, temperature and $\mathrm{pH}$ value, respectively.

The RSM results (Fig. 1 \& Fig. S3) revealed the interactions among the experimental parameters. As the results shown (Table S3), the fitting model F-value was 3.23 and pvalue was $0.024(<0.05)$, which revealed the quadratic model was significant. The linear coefficients (A, B, C, D), cross product coefficients (AB, AC, AD, BC, BD, CD) were found insignificant $(p>0.05)$, whereas the quadratic coefficients $\left(A^{2}, B^{2}, C^{2}, D^{2}\right)$ exhibited significant effect $(\mathrm{p}<0.05)$. The significant order priority of the four factors on the result was $\mathrm{pH}$ value $>$ time $=$ temperature $>$ solid-liquid ratio, which confirmed the fact that the little longer extraction time [24] with appropriate temperature [25], and neutral $\mathrm{pH}[26]$ may be improved protein extraction.

After calculations, the predictive maximum protein yield (4.525\%) was obtained on the optimizing parameters: 1:40 (g: $\mathrm{mL}), 2.93 \mathrm{~h}, 35.19{ }^{\circ} \mathrm{C}$ and 10.07 (pH value). For 
optimizing extraction parameters of proteoglycan. content of the proteoglycan from cracked well GLSP (proteoglycan-C) and uncracked well GLSP (proteoglycan-UC) were explored through FTIR, HPLC and Ion chromatography. Following that, the antioxidant, antitumor and antibacterial effects of proteoglycan-C and proteoglycan-UC were compared.

\subsection{FT-IR analysis}

FT-IR is frequently used to analyze functional groups of a compound [27-29]. The FT-IR spectra of proteoglycan-C and proteoglycan-UC are presented in Fig. 2a. The peaks at 1527 and $1664 \mathrm{~cm}^{-1}$ were due to the presence of amide II and amide I respectively, which revealed the isolated compound contained protein fractions [30]. The signals at 2920, 2850,1478,1160, $1078 \mathrm{~cm}^{-1}$ were attributed to the presence of pyranose ring [31]. Moreover, the absorption peaks around 2920, 1620 and $1400 \mathrm{~cm}^{-1}$ were the characteristic absorption peaks of polysaccharide [32] due to $\mathrm{C}-\mathrm{H}$ and $-\mathrm{COOH}$ groups, respectively [24]. The FT-IR results confirmed that the isolated proteoglycan was a polysaccharide and protein complex. Also, there were no obvious differences in 
stained using Coomassie brilliant blue, which revealed the protein was a nonmonomeric protein. Comparing with standard protein molecular weight marker (lane 1), the molecular weight of protein in proteoglycan-C (lane 2-4) was 43 and $95 \mathrm{kDa}$; and the protein contained in proteoglycan-UC (lane 5-7) possessed molecular weight as follows: 55, 72 and $95 \mathrm{kDa}$. The band width of protein with molecular weight 95 $\mathrm{kDa}$ of proteoglycan-UC (lanes 5-7) is wider than that of proteoglycan-C (lanes 2-4), which indicates proteoglycan-UC contains a higher protein content than proteoglycan-

C. The protein obtained in this work was consistent with the protein with molecular range 12 to $150 \mathrm{kDa}$ from Ganoderma boninense [33].

\subsection{Amino acid content and constitution of polysaccharide}

The amino acid content of proteoglycan was determined using HPLC (Fig. 3a \& b). The content of amino acids (e.g. Asp, Glu, Lys) were calculated (Table S4). The Arg content of proteoglycan-UC $(10.74 \%)$ was did not appeared in proteoglycan-C; the content of Lys in proteoglycan-C (6.32\%) was not detected in proteoglycan-UC. The Asn and Gln were not detected in proteoglycan-C and proteoglycan-UC.

The monosaccharide contained in proteoglycan was determined using Ion chromatograph system. The results (Fig. 3c \& d) revealed the presence of several kinds 
proteoglycan-C. Besides, the Glc and Man contents of proteoglycan-UC (524.281,

$6.386 \mu \mathrm{g} / \mathrm{mg}$, respectively) were more than twice of that proteoglycan-C (247.959, $2.667 \mu \mathrm{g} / \mathrm{mg}$, respectively). While the Fuc and Gal content of proteoglycan-UC was $1.186 \mu \mathrm{g} / \mathrm{mg}$ and $7.421 \mu \mathrm{g} / \mathrm{mg}$ respectively, higher content was found in proteoglycan$\mathrm{C}(3.308 \mu \mathrm{g} / \mathrm{mg}$ and $13.320 \mu \mathrm{g} / \mathrm{mg}$, respectively). The Xyl, Fru, Rib and Glc-AC were not detected in proteoglycan-C and proteoglycan-UC. The results confirmed that the effect of GLSP (cracked or uncracked) on the monosaccharide content was significant. Differences in amino acid and monosaccharide content of proteoglycan between cracked and uncracked wall GLSP may be attributed to two main causes. The first is oxidation reactions which occur in cracked wall GLSP. Secondly, Maillard reaction between monosaccharides and amino acids influence ion chromatography detection. The latter can also occur (and impact) during ion chromatography experimental conditions [34].

\subsection{Free radical scavenging activity}

The scavenging effect of ABTS was expressed as Trolox equivalent antioxidant capacity (TEAC), as shown in Fig. 4. The ABTS scavenging activity of proteoglycan$\mathrm{C}$ and proteoglycan-UC $(1 \mathrm{mg} / \mathrm{mL})$ was $73.3 \pm 6.7 \%$ and $47.2 \pm 5.9 \%$, respectively while 
DPPH test. The differences among these amino acid contents might be the key causes responsible for the antioxidant activities differences of the proteoglycans as the peptides contained in the amino acids (His, Phe and Pro) (Tables S4 \& S5) have shown antioxidant activity [35].

\subsection{Hypoglycemic activity in vitro}

Metformin is used for the treatment of type 2 diabetes, and is a commercially available hypoglycemic drug [36]. Numerous studies have used this drug to demonstrate hypoglycemic activity, typically as a positive control when examining hypoglycemic effects between various treatment groups. Therefore, metformin was selected to compare hypoglycemic activity of proteoglycan in the current work. The glucose concentration of the supernatant of media after being cultured for $24 \mathrm{~h}$ indicated the capacity of glucose consumption of HepG2 cell. The hypoglycemic potency of proteoglycan on normal HepG2 cells is shown in Fig. 5a. The glucose concentration in the proteoglycan treatment $(10 \mathrm{mg} / \mathrm{mL})$ was comparable with the metformin treatment group $\left(10^{-3} \mathrm{~mol} / \mathrm{L}\right)$. Differences in hypoglycemic effect on normal HepG2 cells between treatment and control groups was not significant. This may be due to normal HepG2 
proteoglycan-C was stronger than proteoglycan-UC, and indicates proteoglycan

370 (concentration of $10 \mathrm{mg} / \mathrm{mL}$ ) exhibits a similar hypoglycemic effect as metformin at a

371 concentration of $10^{-3} \mathrm{~mol} / \mathrm{L}$ on normal $\mathrm{HeG} 2$ cells.

372 The hypoglycemic effect of proteoglycan on insulin-induced insulin resistance type

373 HepG2 cells, which used to imitate T2DM patients [12] is shown in Fig. 5b. The

374 glucose concentration in insulin treatment group $(10.91 \pm 0.56 \mathrm{mM})$ was comparable with that of control $(10.92 \pm 0.18 \mathrm{mM})$, indicating that the insulin-induced insulin resistance type HepG2 cells were constructed successfully. Comparing with control, the hypoglycemic effect of resulting proteoglycan-C and proteoglycan-UC on insulin resistance type HepG2 cells were obvious, for the $\mathrm{P}-<0.05$ (p- value was 0.03 and 0.02 , respectively). Furthermore, the glucose concentration treated by proteoglycan- $\mathrm{C}$ was little lower than that of proteoglycan-UC.

The mechanism under the hypoglycemic effect of the proteoglycan is most likely an interaction between proteoglycan and protein tyrosine phosphatase 1B (PTP1B), which was inhibited via interactions between the carboxyl groups of Asp and Glu and Tyr20, Arg24 and Arg254 active sites of PTP1B [37]. Thus, the differences of Asp and Glu content (Table S4) in proteoglycan-C and proteoglycan-UC were the major causes for the difference in hypoglycemic activity. 
antitumor activity in vitro $[16,38]$. As shown in Fig. 6a, the HeLa cell viability

decreased as treatment dose and time increases. When HeLa cells were treated with 0.5

or $1.0 \mathrm{mg} / \mathrm{mL}$ of proteoglycan-C for $12 \mathrm{~h}$, the cell viability was $95.2 \pm 1.5 \%$ and 72.5

$\pm 1.9 \%$, respectively, and decreased further (to $69.9 \pm 2.6 \%$ and $62.3 \pm 0.9 \%$ ) at the treatment of $48 \mathrm{~h}$. The result of proteoglycan-UC on the cell viability was $90.3 \pm 0.9 \%$ and $78.2 \pm 5.3 \%$ for 0.5 or $1.0 \mathrm{mg} / \mathrm{mL}$ for $12 \mathrm{~h}$, respectively, and then decreased to $69.1 \pm 1.0 \%$ and $58.2 \pm 0.9 \%$ when treated for $48 \mathrm{~h}$, respectively.

The antitumor effect can be visualized via AO/EB dual staining results (Fig. 6). The blank control (Fig. 6b) presented bright green with slight orange fluorescence, indicating most vital cells. At the treatment of proteoglycan-C or proteoglycan-UC (1.0 $\mathrm{mg} / \mathrm{mL}$ ) (Fig. $6 \mathrm{~b} 1 \& \mathrm{c} 1$ ), the green fluorescence was weaker and orange fluorescence was brighter, while little less orange fluorescence showed with lower concentration $(0.5$ $\mathrm{mg} / \mathrm{mL}$ ) treatment (Fig. $6 \mathrm{~b} 2 \& \mathrm{c} 2$ ). This indicates the number of viable cells was less than that of the control and the number of necrotic cells had increased; consistent with previously reported studies [39]. The results confirmed the antitumor activity of proteoglycan, which probably due to the polysaccharide fraction in proteoglycan can stimulate the immune system [40] or suppress the cell growth by inhibiting the activity of Akt and transcription factors AP-1 and nuclear factor-kappa B (NF-kB) [41] . 
Compared to control, the proportion of viable cells for $E$. coli decreased to $89.6 \pm 9.9 \%$ and the necrotic cells proportion increased to $112.5 \pm 9.1 \%$ (Fig. 7a) at the treatment of proteoglycan-C $(1 \mathrm{mg} / \mathrm{mL})$. The proportion of viable and necrotic cells of was $93.6 \pm$ $9.2 \%$ and $107.5 \pm 3.9 \%$ respectively when $E$. coli was treated with proteoglycan-UC $(1 \mathrm{mg} / \mathrm{mL})$. For $S$. aureus (Fig. $7 \mathrm{~b})$, at the treatment of proteoglycan-C $(1 \mathrm{mg} / \mathrm{mL})$, the proportion of viable and necrotic cells was $90.8 \pm 8.7 \%$ and $124.9 \pm 6.5 \%$ respectively. The same treatment of proteoglycan-UC induced the proportion of viable and necrotic cells was $97.5 \pm 5.4 \%$ and $108.4 \pm 7.1 \%$ respectively. Thus, these results indicate the antibacterial activities against $E$. coli and $S$. aureus of proteoglycan-UC were stronger than proteoglycan-C.

The antibacterial properties can be visualized using disk diffusion method [42]. Figs. 7 c1-d2 presents a clear inhibition zone with agar plates coated with $E$. coli and $S$. aureus. The diameter of inhibition zone for S. aureus is larger than that for E. coli (Table 1). The difference in activity is attributed to the bacterial cell type. S. aureus is Grampositive bacteria and restricting entry of nutrients into cells leads to death. E. coli is Gram-negative bacteria and an increase in cell permeability results in death [43]. This is the same case for both proteoglycan-C and proteoglycan-UC, which was consistent with previous works [44]. The probable mechanism was that binding of polysaccharides 


\section{Conclusion}

In summary, the proteoglycan from GLSP was obtained using conventional water extraction. The extraction parameters were optimized through RSM results. The results revealed that the proteoglycan obtained from cracked and uncracked GLSP differed its characteristics with respect to molecular weight, amino acid content, monosaccharide content and antibacterial activity. The proteoglycan-C (from cracked GLSP) possessed smaller molecular weight, higher content amino acid of Lys and monosaccharide of Gal comparing with that proteoglycan-UC (from uncracked GLSP). Moreover, the proteoglycan-UC contained higher content amino acids of Arg, Glc, monosaccharide of Man, and revealed stronger antibacterial effects against E. coli and S. aureus and stronger hypoglycemic effect in vitro than that of proteoglycan-C. Meanwhile, the proteoglycan-C exhibited stronger scavenging effects against ABTS and DPPH radicals. The antitumor effects against HeLa cells of proteoglycan-C were similar to that of proteoglycan-UC. Overall, the obtained results regarding antioxidant, hypoglycemic, antitumor and antibacterial activity revealed that the resulting proteoglycan from GLSP is useful as a functional additive as well as a potential candidate for a therapeutic agent. 


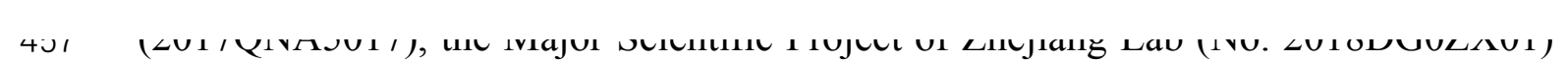

458 and Key Technologies R\&D Program of Zhejiang Province (2015C02035).

459

\section{Competing interests}

461 There are no conflicts of interests to declare. 

edodes mushroom exerts anticancer activities through the transcriptional regulation of cell cycle progression and metastatic markers in human colon cancer cells, The FASEB Journal 31(1_supplement) (2017) lb391-lb391.

471 [3] D. Pan, D. Zhang, J. Wu, C. Chen, Z. Xu, H. Yang, P. Zhou, A novel proteoglycan from 472 Ganoderma lucidum fruiting bodies protects kidney function and ameliorates diabetic nephropathy via its antioxidant activity in C57BL/6 db/db mice, Food. Chem. Toxicol. 63 (2014) 111-118.

[4] C. Zhao, C. Zhang, Z. Xing, Z. Ahmad, J.-S. Li, M.-W. Chang, Pharmacological effects of natural Ganoderma and its extracts on neurological diseases: A comprehensive review, Int. J. Biol. Macromol. 121 (2019) 1160-1178.

[5] Z. Xing, C. Zhang, C. Zhao, Z. Ahmad, J.-S. Li, M.-W. Chang, Targeting oxidative stress using tri-needle electrospray engineered Ganoderma lucidum polysaccharide-loaded porous yolk-shell particles, Eur. J. Pharm. Sci. 125 (2018) 64-73.

[6] C. Zhang, Y. Li, Y. Hu, Y. Peng, Z. Ahmad, J.-S. Li, M.-W. Chang, Porous Yolk-Shell Particle Engineering via Nonsolvent-Assisted Trineedle Coaxial Electrospraying for Burn-Related Wound Healing, ACS Applied Materials \& Interfaces 11(8) (2019) 7823-7835.

[7] C.J. Weng, C. Chifai, Y. Gowchin, J.W. Liao, D.H. Chen, K.D. Chen, Inhibitory effects of Ganoderma lucidum on tumorigenesis and metastasis of human hepatoma cells in cells and animal models, J. Agric. Food. Chem. 57(11) (2009) 5049-57.

[8] S. Wu, J.-S. Li, J. Mai, M.-W. Chang, Three-Dimensional Electrohydrodynamic Printing and Spinning of Flexible Composite Structures for Oral Multidrug Forms, ACS Applied Materials \& Interfaces 10(29) (2018) 24876-24885.

[9] L.-F. Zhu, X. Chen, Z. Ahmad, J.-S. Li, M.-W. Chang, Engineering of Ganoderma lucidum polysaccharide loaded polyvinyl alcohol nanofibers for biopharmaceutical delivery, J. Drug. Deliv. Sci. Technol. 50 (2019) 208-216.

[10] S. Zhang, S. Nie, D. Huang, W. Li, M. Xie, Immunomodulatory effect of Ganoderma atrum polysaccharide on CT26 tumor-bearing mice, Food. Chem. 136(3-4) (2013) 1213-1219.

[11] M.-F. Moradali, H. Mostafavi, S. Ghods, G.-A. Hedjaroude, Immunomodulating and anticancer agents in the realm of macromycetes fungi (macrofungi), Int. Immunopharmacol. 7(6) (2007) 701724.

[12] Z. Yang, F. Wu, H. Yang, P. Zhou, Endocytosis mechanism of a novel proteoglycan, extracted from Ganoderma lucidum, in HepG2 cells, RSC Advances 7(66) (2017) 41779-41786.

[13] S.-K. Eo, Y.-S. Kim, C.-K. Lee, S.-S. Han, Antiherpetic activities of various protein bound polysaccharides isolated from Ganoderma lucidum, J. Ethnopharmacol. 68(1) (1999) 175-181.

[14] P. Saard, R. Sarnthima, S. Khammuang, W. Kanchanarach, Antioxidant, antibacterial and DNA 

Methods 8(5) (2014) 1-9.

513 [18] B. Yang, M. Zhao, P. Knagendra, G. Jiang, Y. Jiang, Effect of methylation on the structure and radical scavenging activity of polysaccharides from longan (Dimocarpus longan Lour.) fruit pericarp, Food. Chem. 118(2) (2010) 364-368.

[19] W.Y. Zhang, J.-J. Lee, I.-S. Kim, Y. Kim, J.-S. Park, C.-S. Myung, 7-O-Methylaromadendrin Stimulates Glucose Uptake and Improves Insulin Resistance in Vitro, Biol. Pharm. Bull. 33(9) (2010) 1494-1499.

519 [20] W. Cui, L. Cheng, H. Li, Y. Zhou, Y. Zhang, J. Chang, Preparation of hydrophilic poly( I -lactide) 520 electrospun fibrous scaffolds modified with chitosan for enhanced cell biocompatibility, Polymer.

$52153(11)(2012)$ 2298-2305.

[21] B. He, H. Tao, A. Wei, S. Liu, X. Li, R. Chen, Protection of carboxymethylated chitosan on chondrocytes from nitric oxide-induced apoptosis by regulating phosphatidylinositol 3kinase/Akt signaling pathway, Biochem Biophys Res Commun 479(2) (2016) 380-386.

[22] S.N. Kulikov, S.A. Lisovskaya, P.V. Zelenikhin, E.A. Bezrodnykh, D.R. Shakirova, I.V. Blagodatskikh, V.E. Tikhonov, Antifungal activity of oligochitosans (short chain chitosans) against some Candida species and clinical isolates of Candida albicans: Molecular weight-activity relationship, Eur. J. Med. Chem. 74(3) (2014) 169-178.

529 [23] D.-Y. Zhang, Y. Wan, J.-Y. Xu, G.-H. Wu, L. Li, X.-H. Yao, Ultrasound extraction of 530 polysaccharides from mulberry leaves and their effect on enhancing antioxidant activity, 531 Carbohydr. Polym. 137 (2016) 473-479.

532 [24] C. Chen, L.J. You, A.M. Abbasi, X. Fu, R.H. Liu, Optimization for ultrasound extraction of 533 polysaccharides from mulberry fruits with antioxidant and hyperglycemic activity in vitro, 534 Carbohydr. Polym. 130 (2015) 122-32.

535 [25] M.E.M. Braga, S.R.M. Moreschi, M.A.A. Meireles, Effects of supercritical fluid extraction on 536 Curcuma longa L. and Zingiber officinale R. starches, Carbohydr. Polym. 63(3) (2006) 340-346.

537 [26] R.E. Poms, C. Capelletti, E. Anklam, Effect of roasting history and buffer composition on peanut 538 protein extraction efficiency, Mol. Nutr. Food. Res. 48(6) (2004) 459-64.

539 [27] Y. Huangfu, K. Ruan, H. Qiu, Y. Lu, C. Liang, J. Kong, J. Gu, Fabrication and investigation on 540 the PANI/MWCNT/thermally annealed graphene aerogel/epoxy electromagnetic interference 541 shielding nanocomposites, Composites Part A: Applied Science and Manufacturing 121 (2019) $542 \quad 265-272$.

543 [28] C. Liang, H. Qiu, Y. Han, H. Gu, P. Song, L. Wang, J. Kong, D. Cao, J. Gu, Superior 544 electromagnetic interference shielding 3D graphene nanoplatelets/reduced graphene oxide 545 foam/epoxy nanocomposites with high thermal conductivity, Journal of Materials Chemistry C 7(9) 546 (2019) 2725-2733.

547 「291 L. Wana. L. Chen. P. Sona. C. Liana. Y. Lu. H. Oiu. Y. Zhana. J. Kona. J. Gu. Fabrication on the 
[33] J.R. Al-Obaidi, N.B. Saidi, S.R. Usuldin, S.N. Hussin, N.M. Yusoff, A.S. Idris, Comparison of Different Protein Extraction Methods for Gel-Based Proteomic Analysis of Ganoderma spp, Protein. J. 35(2) (2016) 100-6.

560 [34] M.P. Colombin, A. Ceccarini, A. Carmignani, Ion chromatography characterization of polysaccharides in ancient wall paintings, J. Chromatogr. A. 968(1-2) (2002) 79-88.

[35] V.U. Girjal, S. Neelagund, M. Krishnappa, Antioxidant Properties of the Peptides Isolated From Ganoderma lucidum Fruiting Body, Int. J. Pept. Res. Ther. 18(4) (2012) 319-325.

[36] D. Lious, L. Fogelfeld, A. Amblee, Combination of Saxagliptin and Metformin Is Effective as Initial Therapy in New-Onset Type 2 Diabetes Mellitus With Severe Hyperglycemia, The Journal of Clinical Endocrinology \& Metabolism 101(6) (2016) 2528-2535.

[37] G. Liu, Z. Xin, H. Liang, C. Abadzapatero, P.J. Hajduk, D.A. Janowick, B.G. Szczepankiewicz, Z. Pei, C.W. Hutchins, S.J. Ballaron, Selective protein tyrosine phosphatase 1B inhibitors: targeting the second phosphotyrosine binding site with non-carboxylic acid-containing ligands, J. Med. Chem. 46(16) (2003) 3437-40.

[38] M.G. Ignatova, N.E. Manolova, R.A. Toshkova, I.B. Rashkov, E.G. Gardeva, L.S. Yossifova, M.T. Alexandrov, Electrospun Nanofibrous Mats Containing Quaternized Chitosan and Polylactide with In Vitro Antitumor Activity against HeLa Cells, Biomacromolecules. 11(6) (2010) 1633-1645.

[39] W.A. Elkhateeb, G.M. Zaghlol, I.M. Elgarawani, E.F. Ahmed, M.E. Rateb, A.M. Abdel, Ganoderma applanatum secondary metabolites induced apoptosis through different pathways: In vivo and in vitro anticancer studies, Biomedicine \& pharmacotherapy = Biomedecine \& pharmacotherapie 101 (2018) 264-277.

578 [40] X.L. Zhu, A.F. Chen, Z.B. Lin, Ganoderma lucidum polysaccharides enhance the function of 579 immunological effector cells in immunosuppressed mice, J. Ethnopharmacol. 111(2) (2007) 219580226.

581 [41] S.J. Chen, H.H. Lin, W.C. Huang, P.J. Tsai, W.P. Chen, D.C. Chen, L.T. Chuang, Ling-Zhi-8 582 protein (LZ-8) suppresses the production of pro-inflammatory mediators in murine microglial BV5832 cells, Food. Agric. Immunol. 28(6) (2017) 1393-1407.

584 [42] H. Wang, T.B. Ng, Ganodermin, an antifungal protein from fruiting bodies of the medicinal 585 mushroom Ganoderma lucidum, Peptides. 27(1) (2006) 27-30.

586 [43] L.F. Zhu, Z.C. Yao, Z. Ahmad, J.S. Li, M.W. Chang, Synthesis and Evaluation of Herbal Chitosan 587 from Ganoderma Lucidum Spore Powder for Biomedical Applications, Sci. Rep. 8(1) (2018) 14608. 588 [44] I.C.F.R. Ferreira, S.A. Heleno, F.S. Reis, D. Stojkovic, M.J.R.P. Queiroz, M.H. Vasconcelos, M. 589 Sokovic, Chemical features of Ganoderma polysaccharides with antioxidant, antitumor and 590 antimicrobial activities, Phytochemistry. 114 (2015) 38-55.

591 「451 F. He. Y. Yana. G. Yana. L. Yu. Studies on antibacterial activitv and antibacterial mechanism of 
599 Fig. 1. Contour plots (2D) for response surface plots results: a-f corresponding to temperature and

time, $\mathrm{pH}$ and temperature, $\mathrm{pH}$ and time, time and solid-to-liquid ratio, $\mathrm{pH}$ and solid-to-liquid-ratio,

temperature and solid-to-liquid ratio, respectively.

Fig. 2. FT-IR spectroscopy of proteoglycan (a) and SDS-PAGE of crude protein contained in proteoglycan (b): lane 1, molecular weight markers; lane 2-4, proteoglycan-C in triplicate; lane 5-

7, proteoglycan-UC in triplicate.

Fig. 3. Amino acids content of proteoglycan-UC (a) and proteoglycan-C (b); monosaccharides content of proteoglycan-UC (c) and proteoglycan-C (d).

Fig. 4. The antioxidant effects of proteoglycan-C and proteoglycan-UC.

Fig. 5. The hypoglycemic capacity against normal HepG2 cells (a) and insulin resistance type HepG2 cells (b) of proteoglycan.

Fig. 6. Effects of proteoglycan on HeLa cell viability using CCK-8 assay (a); Fluorescent images of HeLa cells morphology of blank control group (b) and treated with proteoglycan-C of $1.0 \mathrm{mg} / \mathrm{mL}$ 
Inhibition zone diameter $(\Phi, \mathrm{mm})$

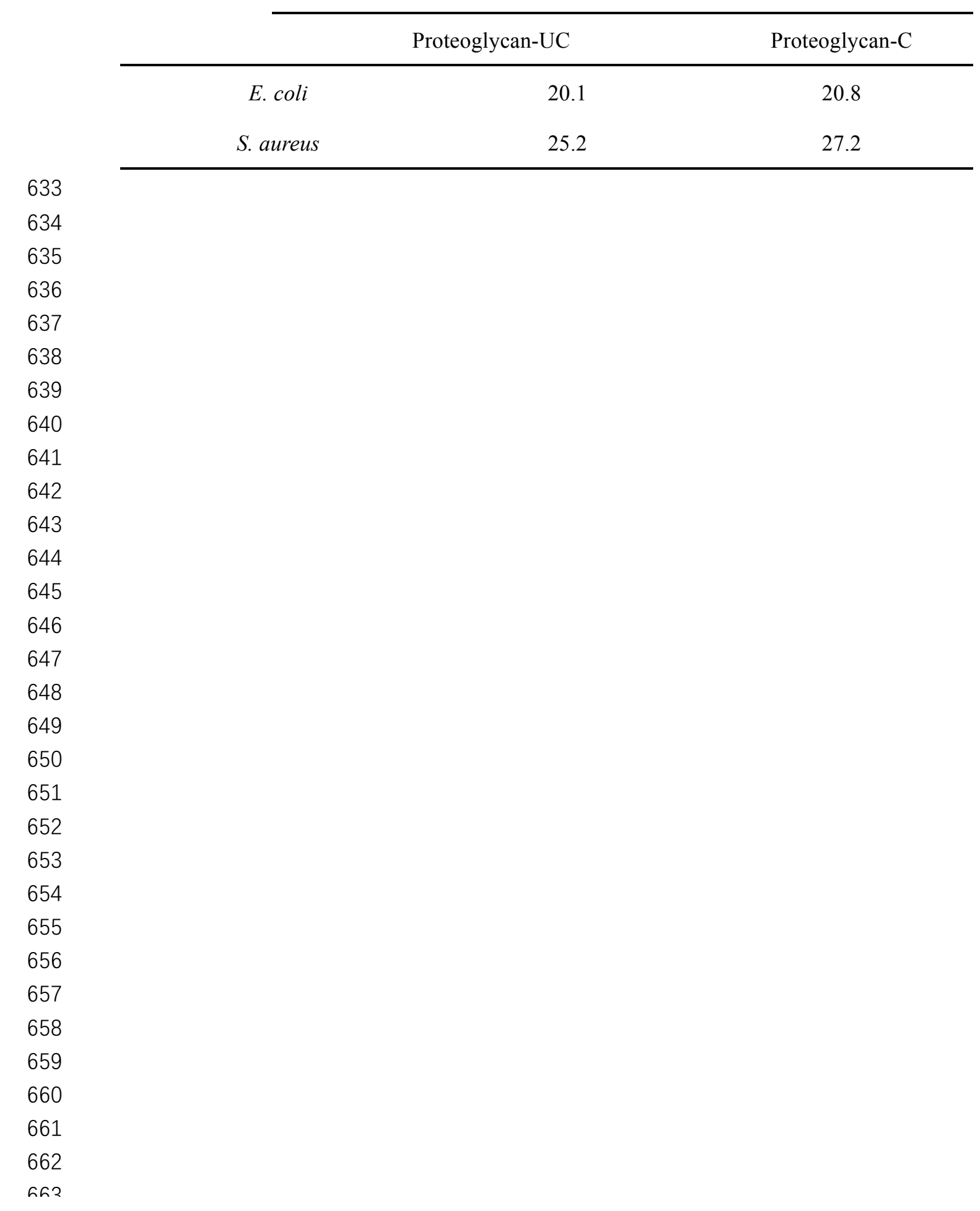


670

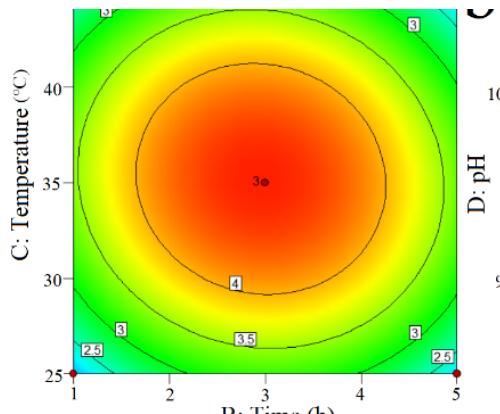

671

672

673

674

675

676

677

678

679

680

681

682

683

684

685

686

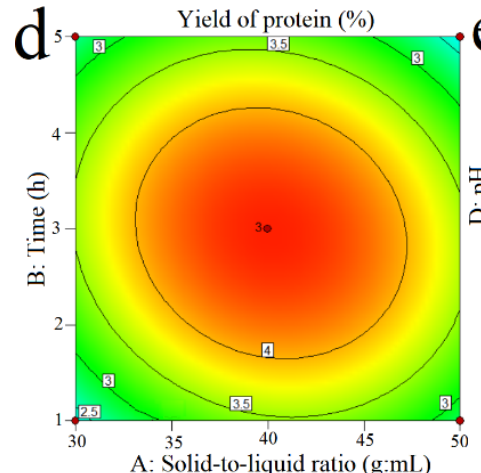

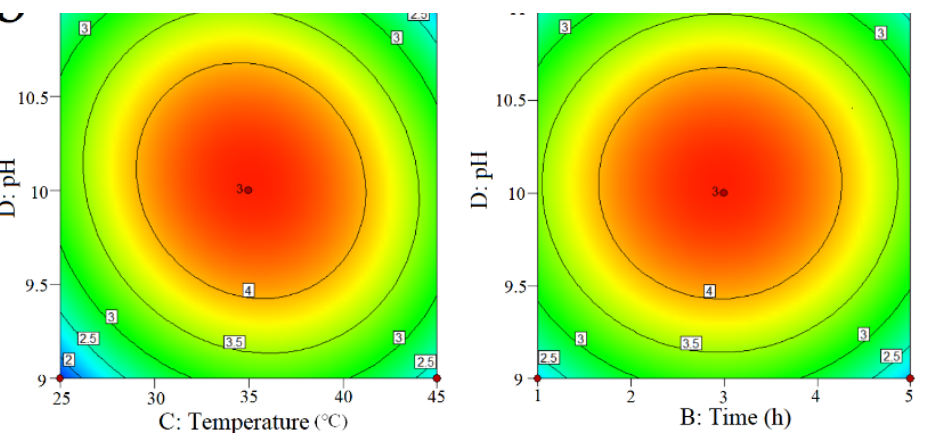
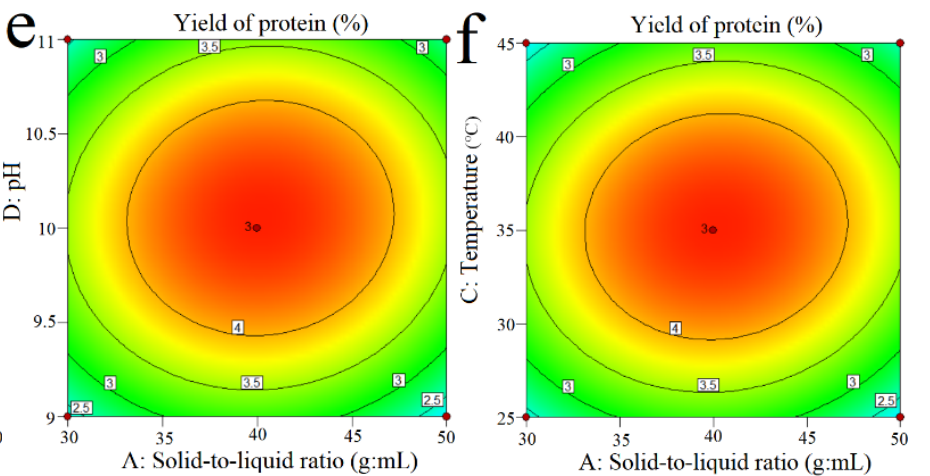

Fig. 1 
687

688

689

690

691

692

693

694

695

696

697

698

699

700

701

702

703

704

705

706

707

708

709

710

711

712

713

714

715

716

717

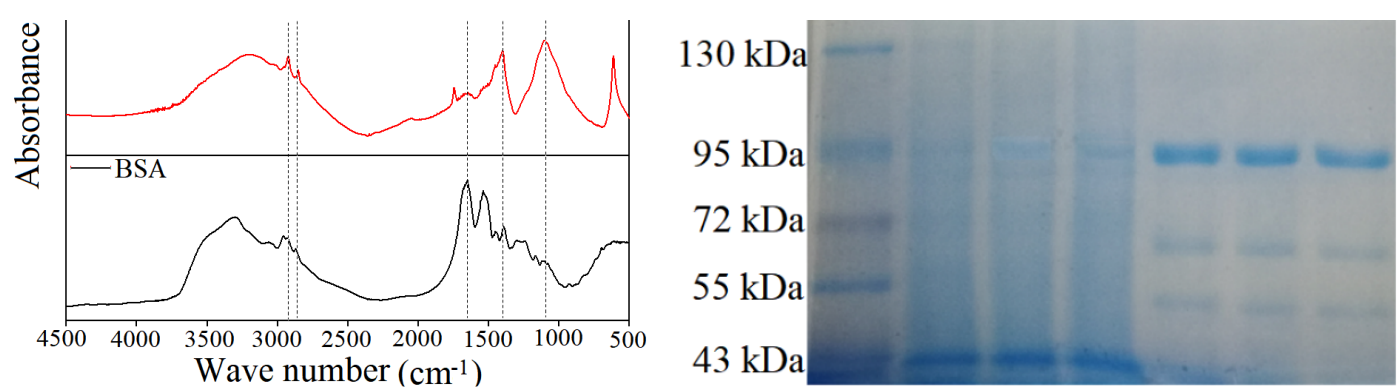

Fig. 2 


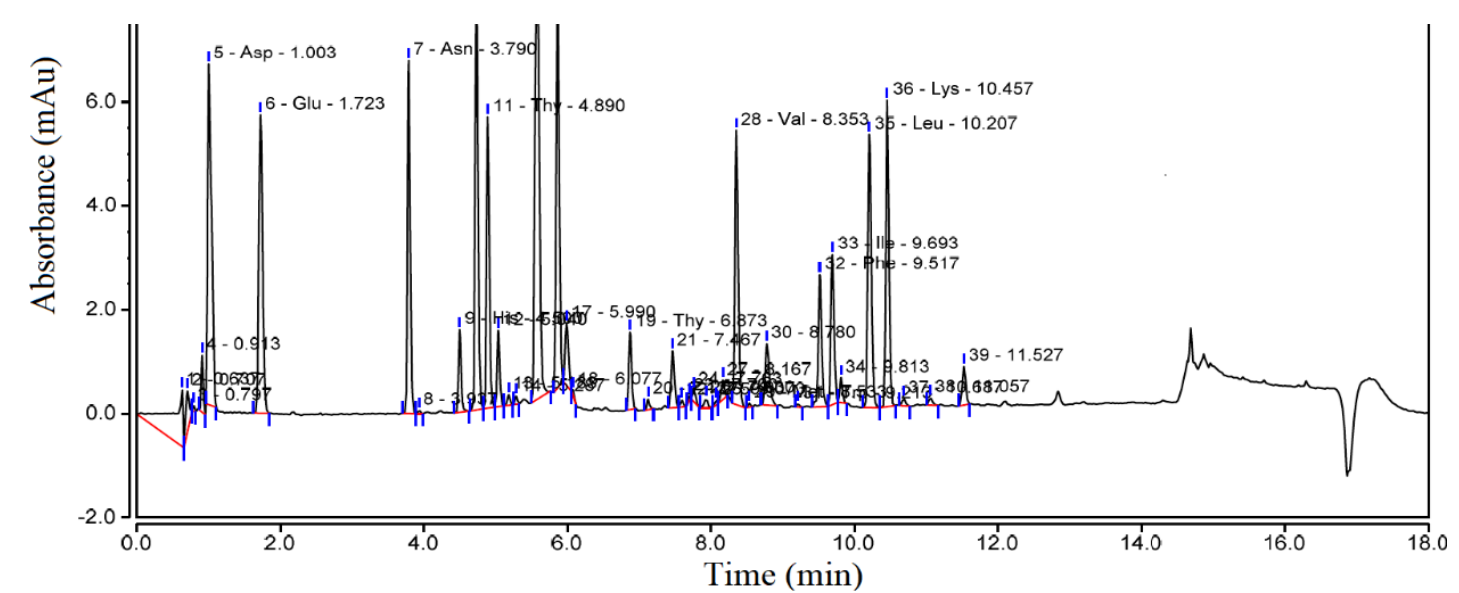

722
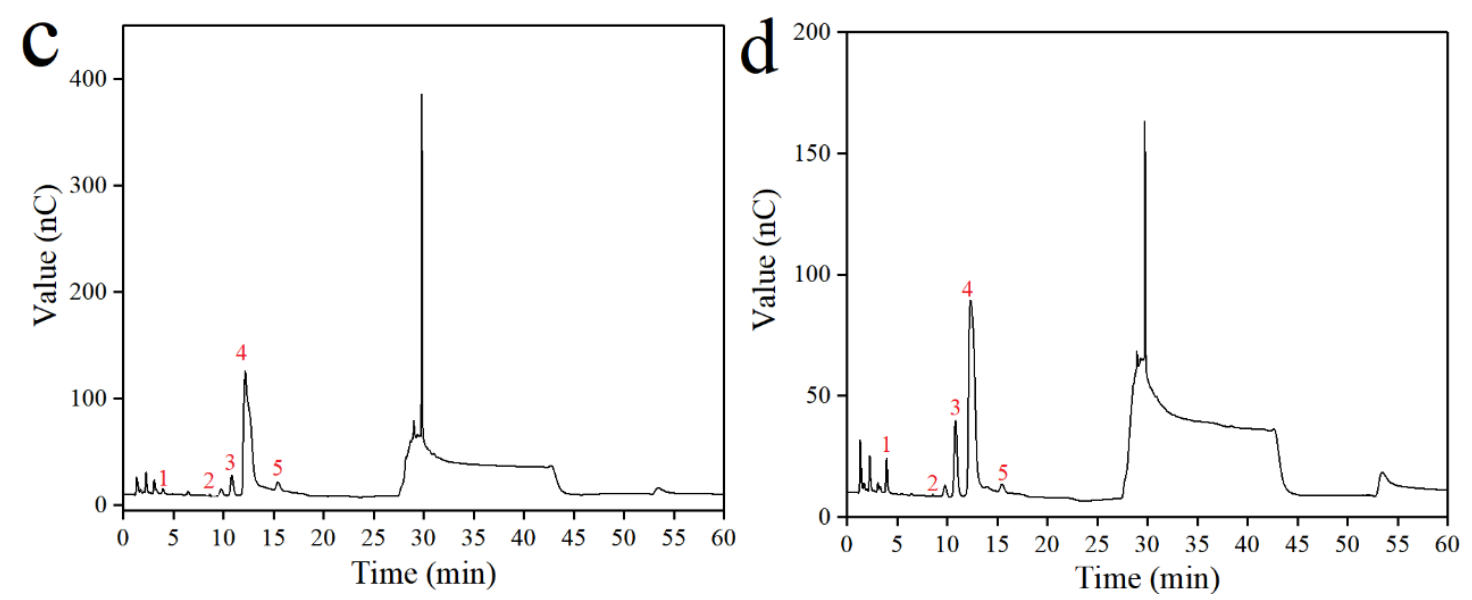

Fig. 3. 


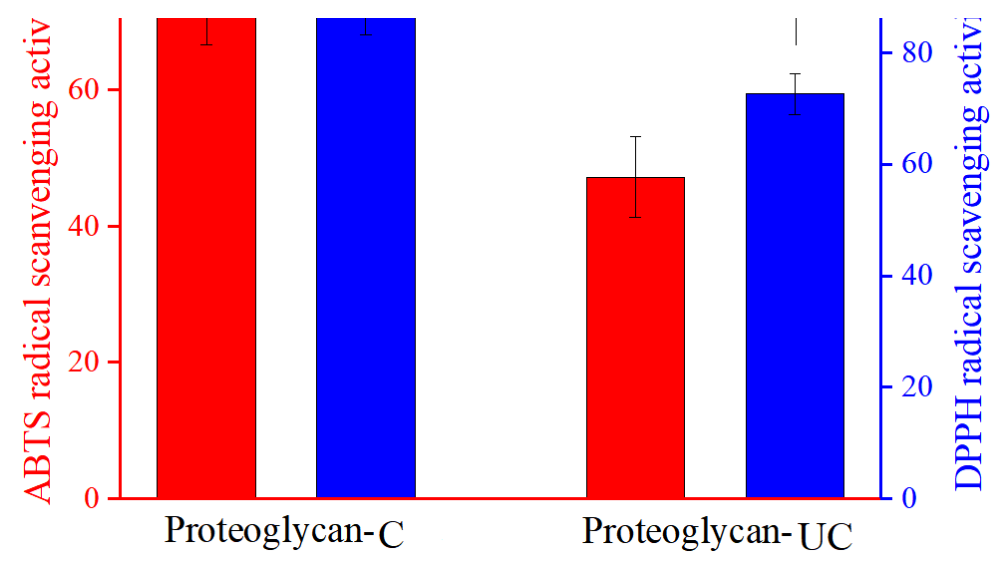

Fig. 4
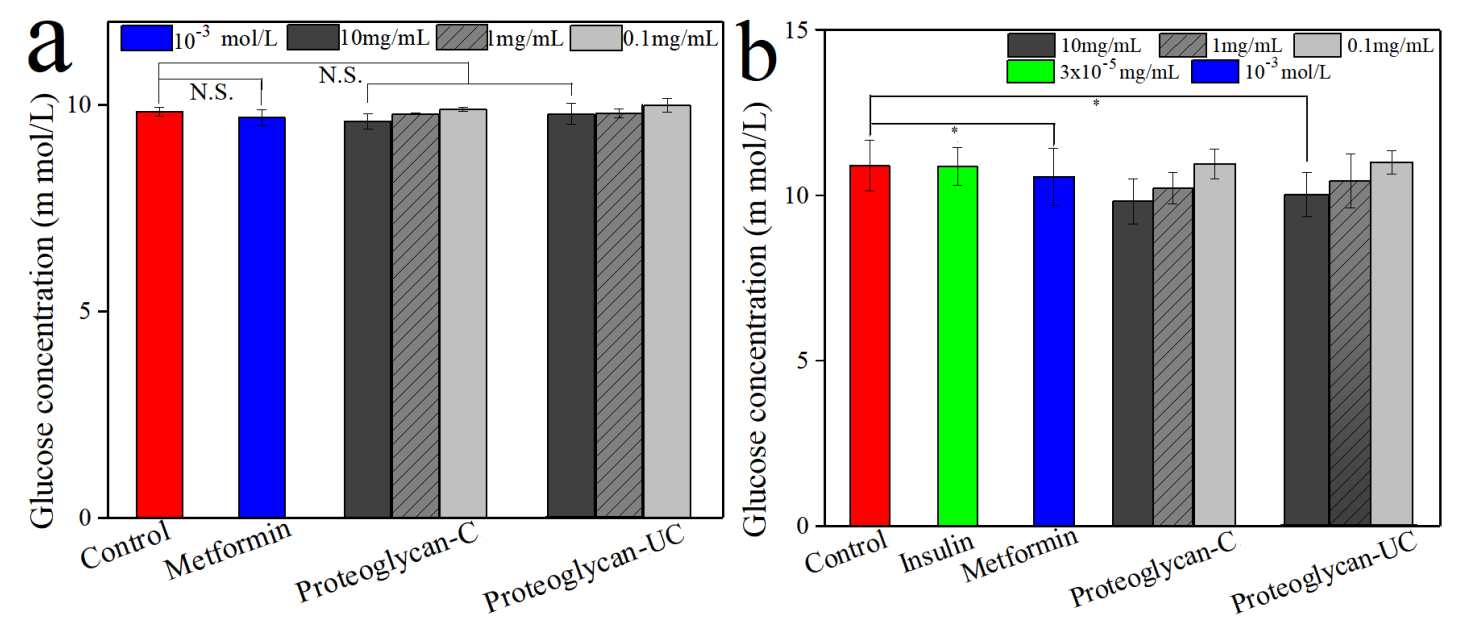

Fig. 5 

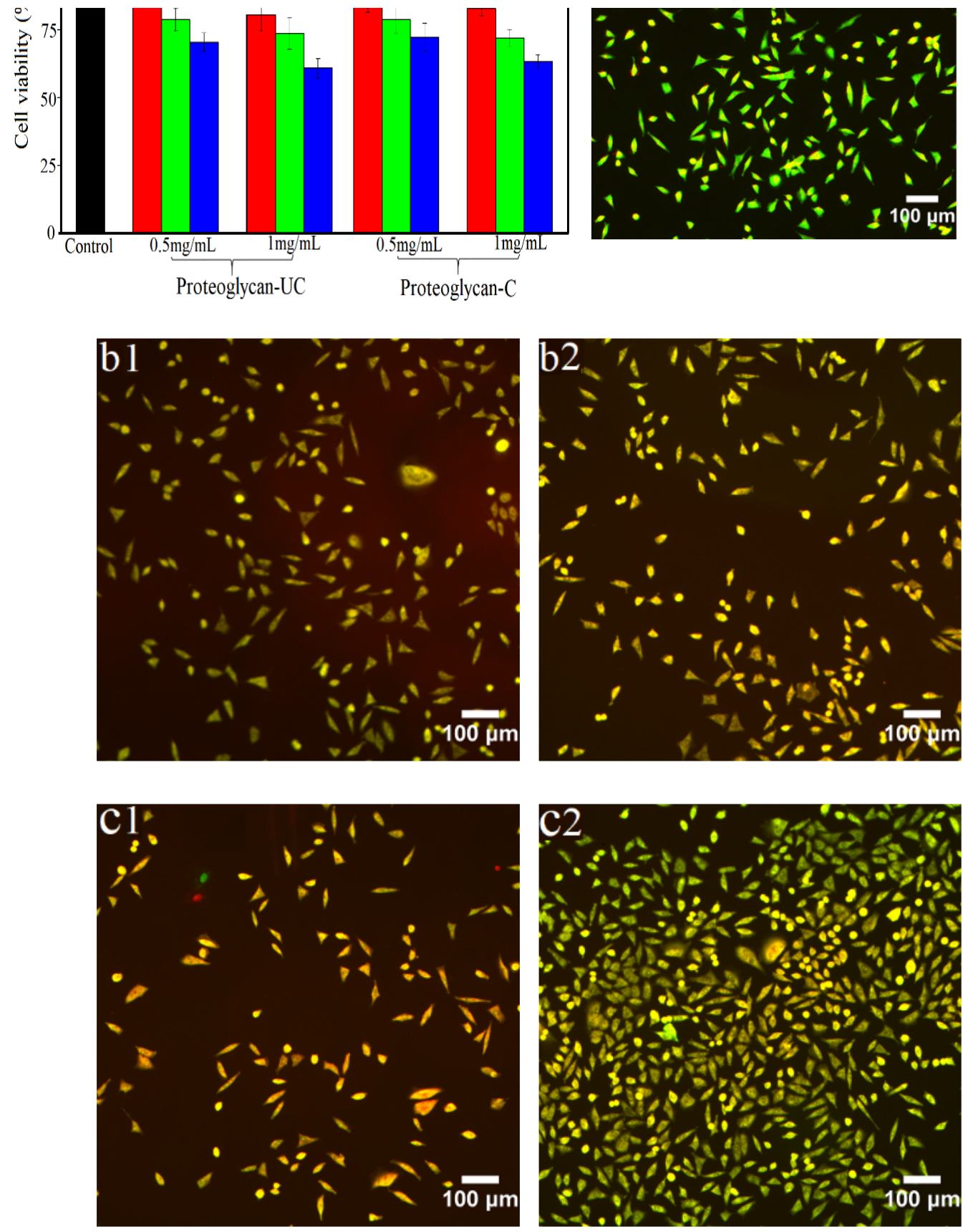


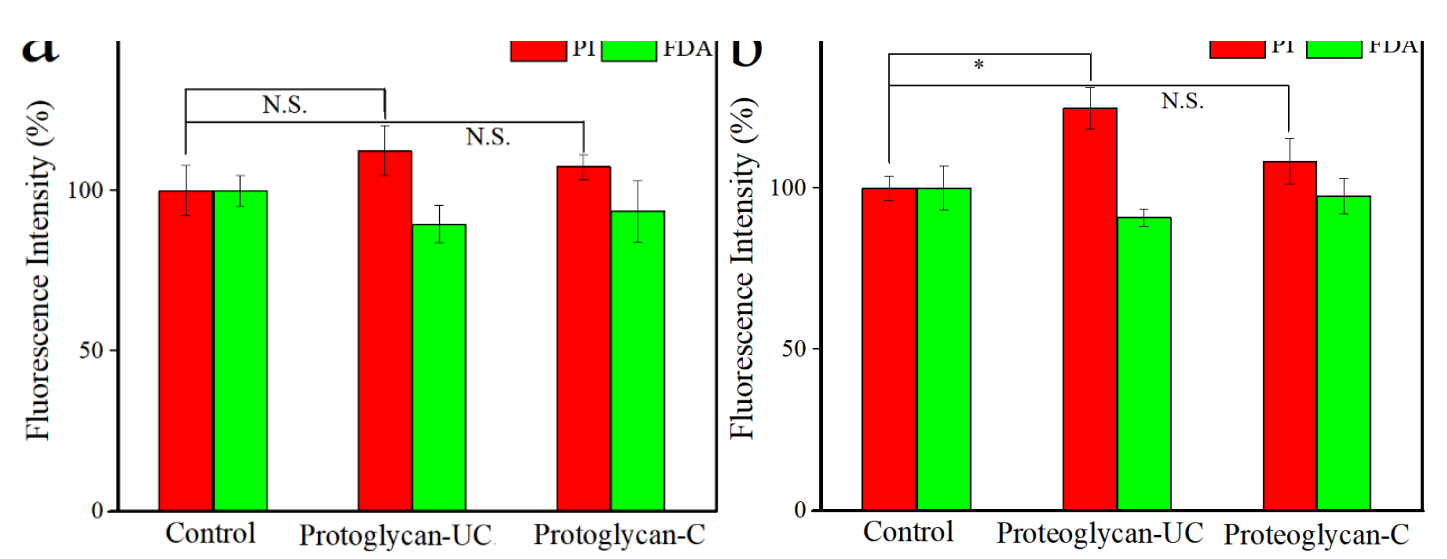

757

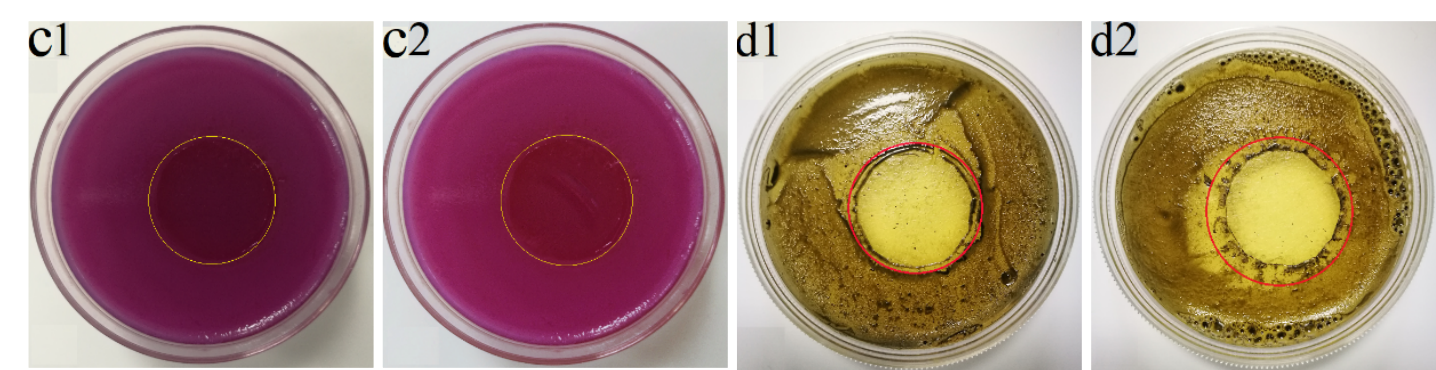

Fig. 7

760

761

762

763

764 